\title{
PROJECTION OF FUTURE STORM SURGES AROUND THE KOREAN PENINSULA BASED ON LARGE ENSEMBLE CLIMATE EXPERIMENTS
}

\author{
Jung-A Yang, Korea University (Former Ph.D Student in Kyoto University), yangia.1985@gmail.com \\ Sooyoul Kim, Tottori University, sooyoul.kim@sse.tottori-u.ac.jp \\ Hajime Mase, Kyoto University, mase.hajime.5c@kyoto-u.ac.jp \\ Nobuhito Mori, Kyoto University, mori@oceanwave.jp
}

\begin{abstract}
INTRODUCTION
Projection of future storm surge height (SSH) based on results of ensemble climate experiments performed using a general climate model (hereafter, GCM) under future climate conditions is ready to start at the regional scale for disaster prevention against storm surge. However, there are limitation to estimate future SSHs with particular return periods which required in coastal structure design because of the lack of sample numbers of storm surge events on local scale. To obtain a large number of samples in localized catastrophic events, Mizuta et al. (2016) carried out an unprecedentedly large ensemble of climate simulations using a high-resolution global climate model over 5000 years. In this study, spatial pattern of storm surge values around the Korean Peninsula (hereafter, the KP) with 100-years return period are assessed based on the large ensemble experiments.
\end{abstract}

\section{MEGA ENSEMBLE CLIMATE EXPERIMENTS}

Two series of experiments with a $60 \mathrm{~km}$ horizontal resolution were conducted: 1) a historical climate simulation and 2) a future climate simulation. The one member of historical climate ensemble experiments was simulated for the period of 1951 to 2010 (60 years), which consists of 100 ensemble members perturbed observed sea surface temperature (SST) errors. The future climate experiment was conducted for the same length of period with 90 ensemble members, assuming that the globalmean surface air temperature becomes $4 \mathrm{~K}$ warmer than the pre-industrial climate. The amplitude of the global warming was held constant over the experimental period. By doing this, large samples under the same specified circumstance of global warming can be obtained.

\section{PROJECTION OF FUTURE STORM SURGE HEIGHTS} AROUND THE KOREAN PENINSULA

Typhoon data extracted from the experiments were employed as external forcing for storm surge simulation around the KP. A series of storm surge simulations were conducted using intensified typhoons with the minimum center pressure of $970 \mathrm{hPa}$ or less for reason of computational expense. The number of the typhoon was 1,428 in the past climate and 1,522 in the future climate which correspond to 6,000 years and 5,400 years of data, respectively. Simulated highest SSHs on each grid in calculation domain were used as maximum values for extreme statistical analysis of the future local storm surge risk in the KP. Figure 1 shows spatial distributions of SSH with 100-year return period in the conditions of past (Fig. $1(\mathrm{a})$ ) and the future change of SSH (Fig. 1(b)). Under the past climate, high SSHs are distributed in the middle areas in the west and south seas of the KP. On the other hand, the significant change of future SSHs is found in the west sea: the future SSH shifts toward the north coast where the mega cities including Seoul are located. In addition, the change in the south sea is seen toward the west coast under the future climate. This regional characteristic of future SSH change where higher SSHs occur is highly dependent on the typhoon intensity change as well as typhoon track shift (refer to Fig. 2(b)). The results project that the $\mathrm{SSH}$ around the KP increase under the future climate except for some areas in the south sea. Magnitude of future change of the $\mathrm{SSH}$ varies spatially. The maximum variation was estimated up to $0.61 \mathrm{~m}$ $(15.4 \%)$ on the west coast of the southeastern sea in the Korean Peninsula.
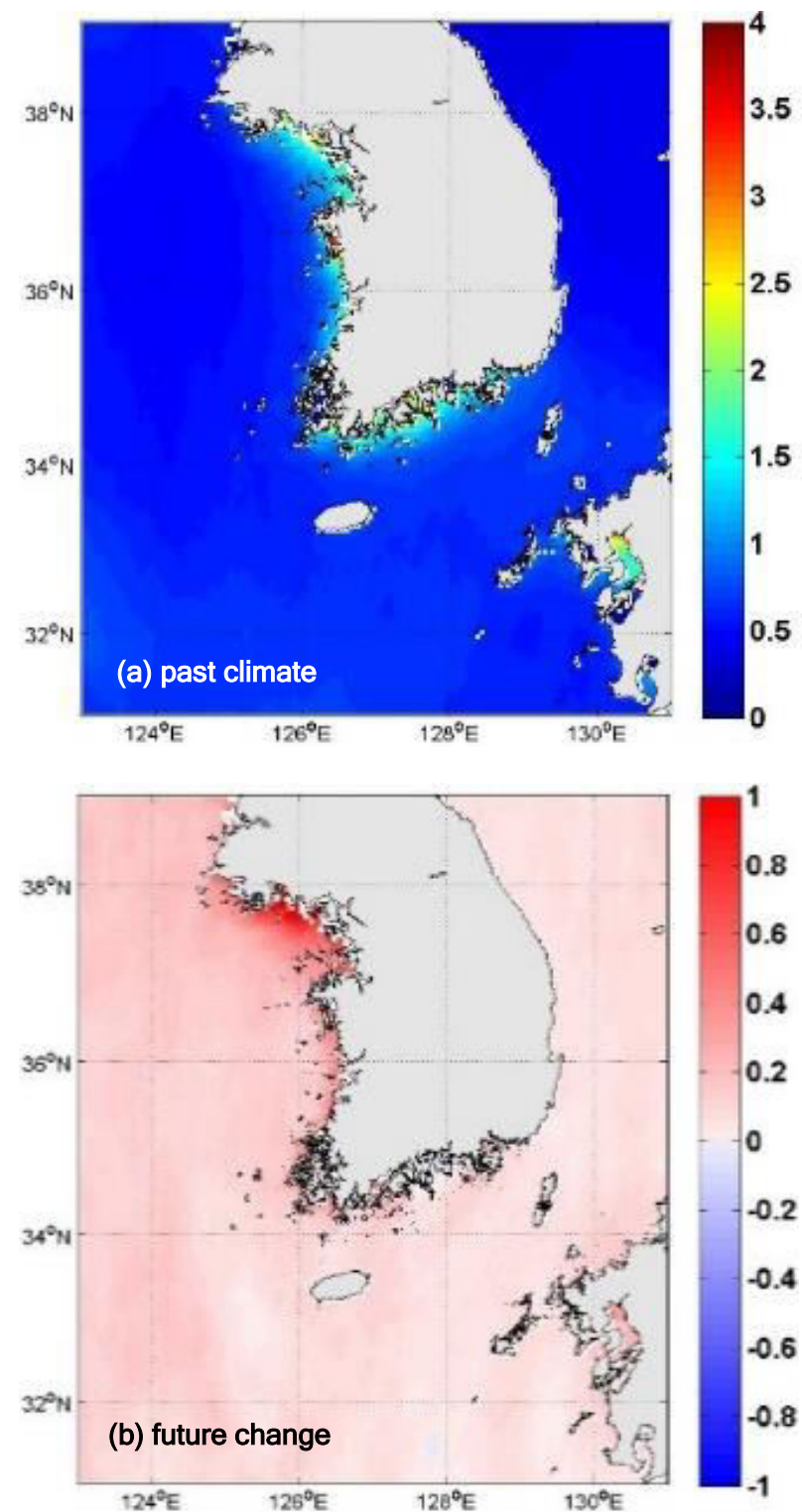

Figure 1 - Spatial distributions of storm surge heights $(\mathrm{m})$ with 100-year return period around the Korean Peninsula 


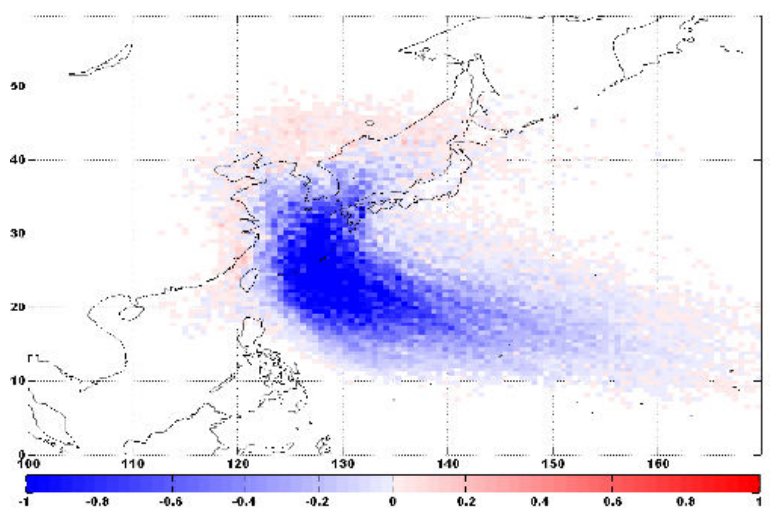

Figure 2 - Future change of annual number of typhoons affecting the Korean Peninsula passing through each grid. Blue and red colors in legend mean the decrease and increase, respectively

Yasuda et al. (2014) reported that SSHs around the KP under the future climate would increase along the south coast and decrease along the west coast, being in disagreement with our findings. This disagreement resulted from the number of ensemble experiments, reproducibility of typhoons and calibration of minimum center pressure of typhoons.

\section{REFERENCES}

Mizuta et al. (2016): Over 5000 years of ensemble future climate simulations by $60 \mathrm{~km}$ global and $20 \mathrm{~km}$ regional atmospheric models. Bulletin of the American Meteorological Society, in press.

Yasuda, Nakajo, Kim, Mase, Mori and Horsburgh (2014): Evaluation of future storm surge risk in East Asia based on state-of-the-art climate change projection. Coastal Engineering, 83, pp. 65-71. 